\title{
Rehabilitation Priority Determination of Water Pipes Based on Hydraulic Importance
}

\section{Do Guen Yoo ${ }^{1}$, Doosun Kang ${ }^{2}$, Hwandon Jun ${ }^{3}$ and Joong Hoon Kim ${ }^{4, *}$}

1 Research Center for Disaster Prevention Science and Technology, Korea University, Seoul 136-713, Korea; E-Mail: godqhr425@korea.ac.kr

2 Department of Civil Engineering, Kyung Hee University, 1732 Deogyeong-daero, Giheung-gu, Yongin-si 446-701, Gyeonggi-do, Korea; E-Mail: doosunkang@khu.ac.kr

3 Department of Civil Engineering, Seoul National University of Science and Technology, 172, Gongreung 2-dong, Nowon-Gu, Seoul 139-743, Korea; E-Mail: hwjun@snut.ac.kr

4 School of Civil, Environmental and Architectural Engineering, Korea University, Anam-ro 145, Seongbuk-gu, Seoul 136-713, Korea

* Author to whom correspondence should be addressed; E-Mail: jaykim@korea.ac.kr; Tel.: +82-2-3290-3316; Fax: +82-2-928-7656.

\section{External Editor: Markus Disse}

Received: 18 August 2014; in revised form: 22 November 2014 / Accepted: 2 December 2014 / Published: 8 December 2014

\begin{abstract}
This paper describes a study conducted to develop a method to facilitate more reliable determination of the rehabilitation priority order for water pipes by taking into account the pipes' hydraulic importance. Existing methods use only the pipeline deterioration rate to determine the rehabilitation priority order. Accordingly, the deterioration rate under normal conditions and the hydraulic importance under abnormal conditions of water distribution pipelines were classified according to two different attributes. The deterioration rate of a water distribution pipeline was calculated in terms of the deterioration rate due to pipeline information factors and the deterioration rate resulting from the installation environment/external factors. The hydraulic importance of water distribution pipelines was calculated by considering the importance of a single pipe failure caused by water leakage or an accident and that of a multiple pipe failure caused by a disaster, such as an earthquake. These four attribute factors were employed in a multi-criteria decision-making process called a weighted utopian approach, developed in this study, that determines the final rehabilitation priority order for each pipeline. The study results indicate that the rehabilitation priority order can be
\end{abstract}


determined more easily using this approach than with previously-developed methods and that the model developed is easier and more convenient to apply than existing rehabilitation priority order models that require a large amount of data, as well as complex failure probabilities and mathematical models.

Keywords: rehabilitation priority; water pipes; hydraulic importance; decision making

\section{Introduction}

A water distribution system is an important part of the social infrastructure, facilitating water transport, distribution and supply. Such a system is a highly complicated network that combines pipelines, pumps and valves. Hence, the facilities in any such system should be continuously improved and updated based on specific plans to maintain the stability and safety of the water supply. As the importance of maintaining and managing this water distribution system has increased, projects for repairing and replacing deteriorating water pipes are currently being undertaken throughout Korea. However, the current methods used to deal with deteriorating pipelines involve an evaluation of the degree of deterioration based on empirical means, as well as reactive rehabilitation projects undertaken after accidents, leading to economic losses and failure to improve system functions. The current approach to determining the rehabilitation priority order for pipelines is based only on the year of installation of the pipes, with no clear criteria for evaluating the degree of deterioration. To address these problems, a new approach to determine the rehabilitation priority order for a water distribution system should be developed that overcomes the drawbacks of the existing methods. In addition, the rehabilitation priority order should be determined according to not only the physical deterioration rate of individual pipes, but also the relative importance of those pipes, to increase the overall stability and safety of the system.

Early studies of the methods to determine the rehabilitation priority order for water distribution systems were conducted using rehabilitation models based on empirical determination that use only general guidelines. Subsequent studies on the determination of the rehabilitation priority order can be broadly classified into the categories of analysis of the deterioration rate and failure probability, regression analysis coupled with failure probability analysis and priority order estimation based on economic feasibility analysis. The Guidance Manual-Water Mains Evaluation for Rehabilitation/Replacement published by the American Water Works Association Research Foundation [1] proposes physical strength, water quality in the pipes, hydraulic conditions and water leakage as criteria for evaluating pipeline functionality. Accordingly, the manual notes that comprehensive management that considers these four criteria is required to effectively maintain and manage water distribution pipelines. The Water Research Centre [2] of the United Kingdom states that it is reasonable to prioritize the repair and rehabilitation of water distribution pipes that are frequently associated with accidents. K-water [3] determined pipeline deterioration rates and developed a weighting system for pipeline repair and rehabilitation by collecting and summarizing domestic and international literature, as well as data on large-diameter water distribution pipes in metropolitan water distribution systems. Subsequently, K-water developed a model to estimate the deterioration rate of water pipes using a point-based evaluation method that considers the estimated pipe condition and weight, as well as a model for prioritizing the replacement and rehabilitation of water 
pipes. However, this model is limited in that the point-based evaluation method does not reflect the hydraulic characteristics of water distribution systems. Kim et al. [4] re-calculated the cost function by modifying and complementing the failure rate function proposed by Shamir and Howard [5]. In addition, they estimated the deterioration rate using a probabilistic neural network (PNN) and proposed a rehabilitation model that prioritizes the rehabilitation and replacement of pipes using a shortest-path model. Studies in which regression analysis and failure probability analysis have been applied to estimating the rate of deterioration of water pipes have been conducted by Marks and Clark [6,7], Agbenowosi [8] and Park and Loganathan [9,10]. Marks and Clark [6,7] proposed a method for failure modeling based on the deterioration rate of the water distribution pipes. After classifying the deterioration status of water distribution pipes into "early stage", with a small number of failures, or "later stage", with a large number of failures, their method applies these stages to each case. Based on their results, they proposed that the deterioration status of a water distribution pipe could be represented by a proportional hazards model in the early stage and a Poisson-type model in the later stage. Deb et al. [11] classified water distribution pipes according to their installation year, pipe material, diameter and backfilled soil type. They also developed a probabilistic model called "KANEW" based on this classification to estimate the number of pipes in a water distribution system that should be replaced annually. Agbenowosi [8] represented the factors related to water distribution pipes in a pipe load model and a pipe break model, so that the factors could be analyzed mathematically and the most economical time at which to replace a water distribution pipe could be determined. Park and Loganathan $[9,10]$ proposed a failure estimation model for water distribution pipes using a threshold break rate. Using this model, the economically optimal replacement time is determined as a function of the costs of pipe replacement and rehabilitation, a discount rate and the length and diameter of the pipes.

In general, these models, which determine the rehabilitation priority order of pipes in water distribution systems using regression and failure probability analyses, predict pipe failure through complex formulas and determine the most economical replacement and rehabilitation times through economic feasibility analysis. While these models can predict pipe failure through failure probability analysis, they require a large amount of basic data and complex formulas to produce results. Models for determining the rehabilitation priority order of pipes in water distribution systems on the basis of economic feasibility, which have been examined by Shamir and Howard [5], Walski [12] and Luong and Fujiwara [13], achieve maximum efficiency at minimum cost. Alvisi and Franchini [14] proposed a near-optimal rehabilitation scheduling method based on a multi-objective genetic algorithm. With reference to a fixed time horizon, the goal is to minimize the overall costs of repairing and/or replacing pipes and to maximize the hydraulic performances of the water network. However, given that these models also require a large amount of basic data and that water distribution pipes are part of social infrastructure networks that directly affect public welfare, cost optimization cannot be an essential condition.

In recent years, computer-aided models and decision support tools, such as Care-W [15-21], CASSES [22] and AWARE-P [23], have been developed. The CARE-W project aimed to develop methods and software that would enable engineers of the water undertaking to define and implement an effective management of their water supply networks, rehabilitating the right pipelines at the right time. This project was organized in eight work packages (WP), which were the construction of a control panel of performance indicators (WP1), description and validation of technical tools (WP2), elaboration of a decision support system for annual rehabilitation programs (WP3), elaboration of long-term strategic 
planning and investment (WP4), elaboration of the CARE-W prototype (WP5), testing and validation of the CARE-W prototype (WP6), dissemination (WP7) and project management (WP8). CARE-W used four probabilistic forecast failure models (proportional hazard model, Markov model, Poisson analysis, and non-homogeneous Poisson process) and three mathematical hydraulic reliability assessment models (Aquarel, Failnet-Reliab, Relnet). Among these WPs, WP3 and WP4 focused on the determination of priority and scheduling for rehabilitation according to the target time period (one year and long-term plan). They used multi-criteria techniques, such as scoring and ELETRE TRI methods, to determine relevant procedures during annual rehabilitation programs. In case of long-term rehabilitation strategies, extended KANEW is used. In the continuation of CARE-W, a new break prediction model, called linear extension of the Yule process (LEYP), was developed. It involved a statistical model based on a counting process and relied not only on the pipe's characteristics and environment, but also its age and previous breaks. This new model was chosen to be used in the development of the break prediction software, CASSES. The main result from this software was the number of breaks for each pipe for a period in the future. The AWARE-P project has been performed for providing water and wastewater utilities with the know-how and the tools needed for efficient decision-making in infrastructural asset management (IAM) of urban water services. The key point of this project is IAM as a management process, based on plan-do-check-act (PDCA) principles and requiring alignments between the organization's strategic objectives and targets and the actual priorities and actions implemented.

Water distribution pipes can be divided into hydraulically significant or insignificant pipes depending on the installation location, valve location, base demand for water at nodes, variation in demand, pipe flow rates and the population served. Accordingly, the importance of individual water distribution pipes can be termed "hydraulic importance." This study was conducted to develop a method to determine the rehabilitation priority order of pipes in water distribution systems on the basis of both the deterioration rate of water pipes and their hydraulic importance. Using the method proposed in this paper, pipes are first classified according to their deterioration rate and hydraulic importance according to two different attributes. A multi-criteria decision-making method called a weighted utopian approach, which combines a weighting method and a distance measurement method, is then used to prioritize the pipes' rehabilitation needs.

\section{Methodologies}

In this study, the deterioration rate under a normal situation and hydraulic importance under abnormal conditions of water distribution pipes were used to determine the rehabilitation priority order of pipes in a water distribution system, as shown in Figure 1. The deterioration rate was divided into two components: the deterioration rate due to internal factors and the deterioration rate due to installation environment factors (external factors). The hydraulic importance was also divided into two components: the importance related to single pipe failure (which accounts for most pipe accidents) and the importance related to multiple pipe failures due to disasters, such as earthquakes. 
Figure 1. Attributes for rehabilitation priority order.

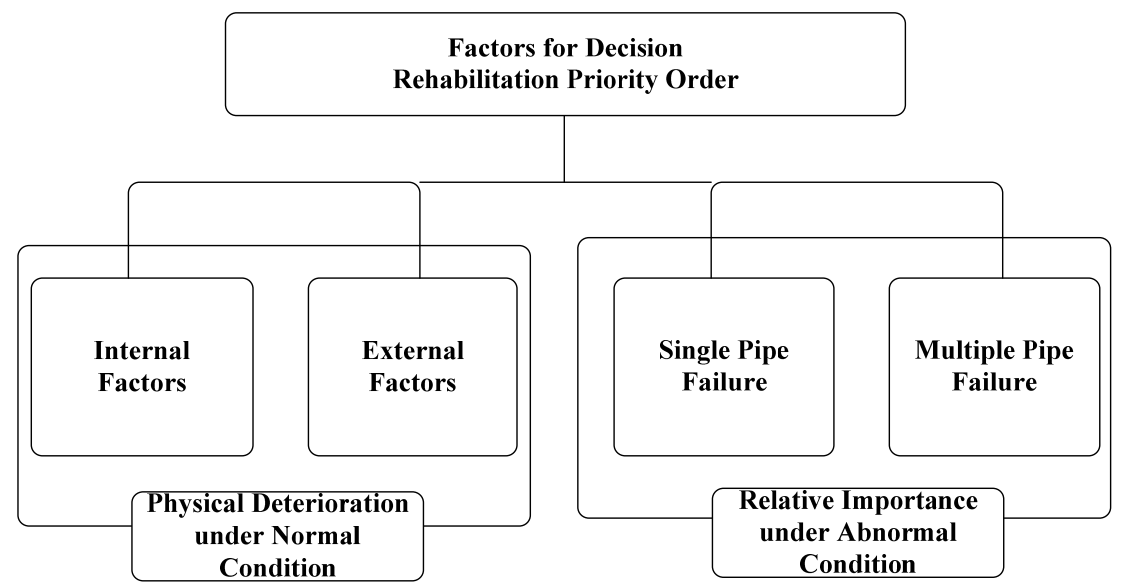

\subsection{Pipe Deterioration}

In this study, the deterioration rate calculation method and factors proposed by Kim et al. [4] were considered, and a total of 12 factors were classified as either internal or external factors. Eight internal factors were identified: pipe material, pipe diameter, interior corrosion rate, elapsed time since installation, type of joint, record of leakage and breakage, record of civil appeals regarding water quality and pressure and maximum pipe pressure. Four external factors were identified: exterior corrosion rate, backfilled soil type, road width and installation district. To quantify the deterioration rate, weights for the factors should be taken into consideration. From among the methods available for determining such weights, an eigenvector method employed for weight calculation in an analytic hierarchy process (AHP) [24], a decision-making method, was selected for use in this study.

A PNN model proposed by Specht [25] was employed to take the weight of each factor into consideration in calculating the degree of deterioration. To apply this PNN model to the prioritization method developed in this study, the conditions of the factors should be classified according to conditional values. For example, the factors that are most heavily influenced by the deterioration rate are assigned a value of 1.0, and those that are influenced the least are assigned a value of 0.0 . The conditions that have the greatest influence on a factor are assigned a value of 1.0, and those with the least influence are assigned a factor of 0.0 . The conditions of factors, such as the exterior corrosion rate, backfilled soil type, road width and installation district, which are used to calculate the possibility of water distribution pipes failing due to installation environment/external factors, were classified according to a total of five conditional values. The relative weight of each factor is then calculated using the eigenvector method. The PNN model applied in this study consists of input, pattern, summation and output layers, as illustrated in Figure 2. In the input layer, a conditional value defined according to conditions for standard pipes is assigned to each neuron, while five large neurons are placed in the pattern layer, with one large neuron being responsible for a certain boundary condition value. A large neuron is one of the main components when we make the structure of a PNN. In this study, a large neuron works as a dividing criterion, which is divided into five deterioration groups among the pipes. That is, the first large neuron includes neurons that have a conditional value of 1 , while the second, third, fourth, and fifth large neurons consist of small learning neurons with conditional values of $0.75,0.5,0.25$ and 0.0 , respectively. The four small learning neurons correspond to the exterior corrosion rate, backfilled soil type, road width 
and installation district, respectively. The pattern layer plays a critical role in identifying input data and performing classification, by measuring the distance between the input data and learning neurons, and includes the calculated distance in the activation function. In the model used in this study, a Gaussian function was used to determine the width and area of the data in the activation function. The summation layer has a single summation neuron that simply adds data learned from the pattern layer. The output layer has five neurons that have a simple classification function. When classification is performed in the output layer, classification is not done based on a percentage value, but by a simple summation of all values obtained in the summation layer, once trained, after the input data are entered. When output values are defined as P1, P2, P3, P4 and P5; P1 means a probability value that is to be included in the neuron responsible for the conditional value of 1 . From among P1, P2, P3, P4 and P5, obtained through the process above, the largest value is selected; if $\mathrm{P} 1$ is the largest value, the deterioration rate of the corresponding pipe is classified into Group 1. For example, if P1, P2, P3, P4 and P5 have values of 0.45, $0.15,0.2,0.15$ and 0.05 , respectively, as a result of calculating the deterioration rate, $\mathrm{P} 1$, which has the largest probability, is selected, and the deterioration rate of the corresponding pipe becomes that corresponding to Group 1. The groups and probability values of the pipes are obtained by using the PNN algorithm to assess the deterioration rate of the pipes based on internal factors and installation environment/external factors. In addition, values are distributed between 0 and 1 using an interpolation method to compare the values for each pipe.

Figure 2. Probabilistic neural networks for assessing pipe deterioration.

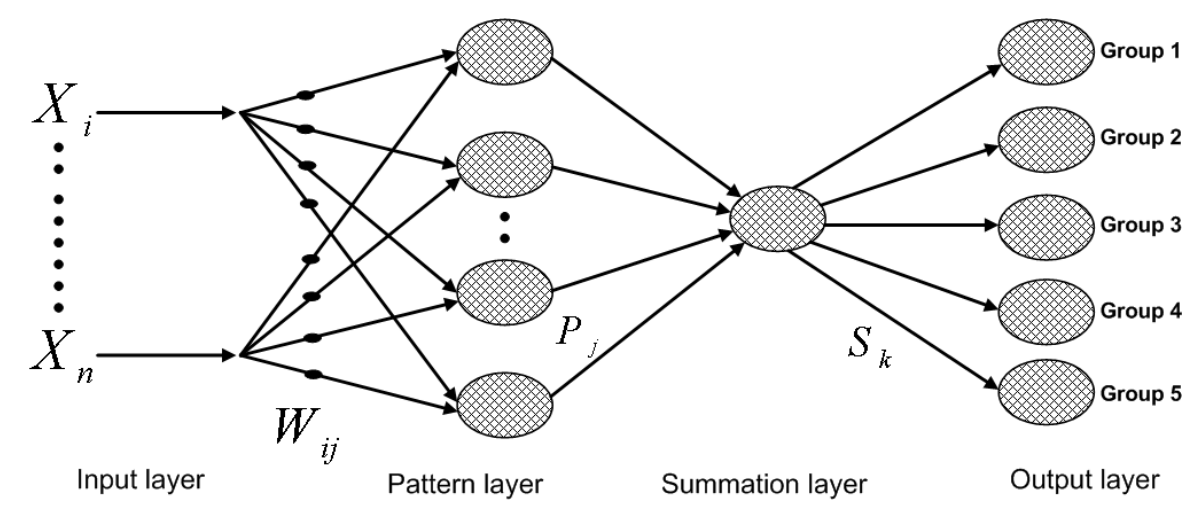

\subsection{Hydraulic Importance: Single Pipe Failure}

Whereas most existing methods restrict the range of damage due to the failure of a water pipe to the corresponding water pipes, Jun et al. [26] introduced the concept of "unintended isolation," in addition to the concept of partial segments in water distribution networks, as proposed by Walski [27], which are used to estimate the damage area due to the failure of water pipes. According to Walski [27], a segment can be defined as a set of surrounding pipes that are closed by water control valves, along with a failed pipe, in the event of a failure. That is, when a failed pipe and the surrounding pipes should be isolated, a segment can be defined as the number of separated water pipes and nodes. When the area of damage is estimated using only failed water pipes, it is limited to those cases in which only the failed water pipes are closed. However, considering the practicalities, adjacent pipes may also have to be closed, depending on the number and locations of the water control valves. For example, Figure 3 shows that when P2 fails, such that the water control valves have to be closed to enable repairs, P4 is also closed. Consequently, 
the water supply to node N1 within the closed segment is also stopped. This damage area estimation method can produce more realistic estimates of the areas of damage, because it considers the number and locations of the water control valves. When a segment that includes a failed water pipe is closed to enable repair, the water supply to other sub-pipes connected to the failed pipes is also shut off if the segment constitutes the only path from the water source. That is, some pipes can experience disconnection of the water supply due to the segment closure. Jun et al. [26] defined this event as unintended isolation and developed an updated breadth-first search algorithm based on a node-arc matrix, which is more advanced than a conventional breadth-first search algorithm, to identify the unintentionally isolated pipes. In the event of unintended isolation, consumers of water in the area are deprived of their supply until the failed water pipe is fixed. That is, even if the supply in the area is not shut down by the water control valves, consumers in the area are isolated from the water supply being provided to those living in the segment. In Figure 3, a segment consisting of P6 and N6 generates unintended isolation.

Figure 3. Segment and unintended isolation [26]. P, probability value; N, node.

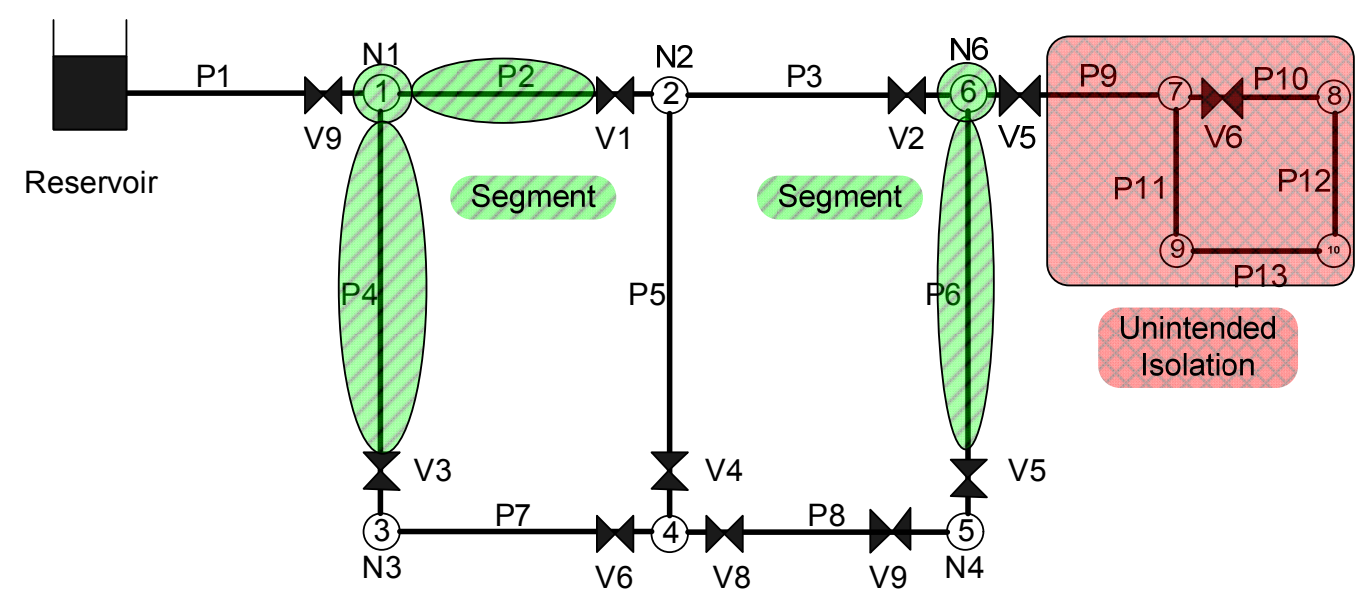

To determine the importance of individual water pipes in the event of a single pipe failure, it is necessary to assume the following: the failure probability of each pipe is the same, and no more than two pipes can fail at any one time. The probability of pipe failure can differ among pipes according to the deterioration rate of the pipe, size, material, etc. In the case of hydraulic importance calculations of single pipe failure simulation, components of failures include not only unintentional failure (e.g., breakage and leakage), but also intentional failure (e.g., cut off the water). In this case, we cannot exactly predict intentional failure. Because of that, we assumed that the failure probability of each pipe is the same. It is also assumed that all of the valves are functioning properly, so valve malfunctions do not have to be considered. Based on these assumptions, the segments and instances of unintended isolation that are generated as a result of a single pipe failure in a water distribution system are calculated, and this calculation process is executed for all pipes. Finally, the importance of an individual water pipe in the event of a single pipe failure is calculated for each of the water pipes, based on Equation (1). The greater the HISPFi (hydraulic importance by single pipe failure when pipe i fails) value of an individual pipe, the higher the relative importance of the pipe in the event of a failure. Conversely, the smaller the HISPFi value, the lower the relative importance of the pipe in the event of a failure.

$$
\operatorname{HISPF}_{\mathrm{i}}=\frac{\mathrm{Q}_{\mathrm{i}, \mathrm{S}}+\mathrm{Q}_{\mathrm{i}, \mathrm{UI}}}{\mathrm{Q}}
$$


where $\mathrm{HISPF}_{\mathrm{i}}=$ hydraulic importance by single pipe failure when pipe i fails; $\mathrm{Q}=$ total pipe flow under normal conditions; $\mathrm{Q}_{\mathrm{i}, \mathrm{s}}=$ segment pipe flow when pipe $\mathrm{i}$ has failed; $\mathrm{Q}_{\mathrm{i}, \mathrm{UI}}=$ unintended isolation pipe flow when pipe $\mathrm{i}$ has failed.

\subsection{Hydraulic Importance: Multiple Pipe Failures}

Because earthquakes typically lead to major damage and multiple pipe failures, the importance of water pipes as evaluated in the event of an earthquake was considered in this study. Yoo et al. [28,29] developed the reliability evaluation model of seismic hazards for water supply networks (REVAS.NET) for use in evaluating seismic risks to water distribution systems. This model is intended to prevent damage from earthquakes by calculating the reliability of a water distribution system in the event of an earthquake. This model was employed in this study. The process by which REVAS.NET was employed and the reliability factors used in this study are as follows:

Step (1) Establishment of basic topological structure of water supply network in the area of application;

Step (2) Construction of fragility curves for each component of a water distribution system;

Step (3) Simulated earthquake generation (seismic location and magnitude);

Step (4) Seismic wave attenuation;

Step (5) Determination of component conditions;

Step (6) Execution of EPANET hydraulic analysis;

Step (7) Negative pressure processing;

Step (8) Calculation of hydraulic reliability of systems/components.

Once the states of the water pipelines, tanks and pump facilities after the simulated earthquake have been determined, these states can be simulated via hydraulic analysis, and the hydraulic analysis results for the water distribution system can be derived. To quantify the results, a reliability factor is used. In general, system reliability, which is a widely-used concept in many fields, refers to the probability of a service running continuously within a system. In REVAS.NET, nodal serviceability ( $\mathrm{N}_{\mathrm{s}}$ ) and system serviceability ( $\mathrm{S}_{\mathrm{s}}$ ) [30-32], which are known to be relevant to a water distribution system, are used as reliability factors.

In this study, the hydraulic importance of water pipelines was calculated using the nodal serviceability (Ns), expressed by Equation (2). In the case of Ns, the hydraulic importance of a node for which nodal demand is required is calculated from the ratio of the available nodal demand to the required nodal demand. The usability of a node at which the required nodal demand is not present is assessed by evaluating the ratio of the pressure after the earthquake to the allowable minimum nodal pressure. This reliability index, which represents the serviceability that each node can provide, is calculated from the required nodal demand and minimum pressure, so it can be used to assess the relative supply ability per node.

$$
\text { Nodal Serviceability }\left(\mathrm{N}_{\mathrm{S}, \mathrm{i}}\right)=\left\{\begin{array}{c}
\frac{\mathrm{Q}_{\mathrm{avl}, \mathrm{i}}}{\mathrm{Q}_{\text {in } \mathrm{i}, \mathrm{i}}} \text { when } \mathrm{Q}_{\text {in } \mathrm{i}, \mathrm{i}} \neq 0 \\
\sqrt{\frac{\mathrm{Min}\left(\mathrm{P}_{\mathrm{i}}, \mathrm{P}_{\min }\right)}{\mathrm{P}_{\min }}} \text { when } \mathrm{Q}_{\text {in } \mathrm{i}, \mathrm{i}}=0
\end{array}\right.
$$


where $\mathrm{Q}_{\text {avl,i }}=$ available nodal demand at node $\mathrm{i} ; \mathrm{Q}_{\text {ini,i }}=$ required nodal demand at node $\mathrm{i} ; \mathrm{P}_{\mathrm{i}}=$ nodal pressure at node $\mathrm{i} ; \mathrm{P}_{\min }=$ allowable minimum nodal pressure.

Finally, the importance of a water pipeline in the event of multiple pipe failures is calculated using Equation (3). The importance can be calculated by subtracting the average reliability value of each node connected to each water pipe from value 1 . The higher the resulting value is, the lower the serviceability of the water pipelines related to the corresponding water pipeline as a result of a corresponding pipeline breakage followed by multiple pipe failures.

$$
\mathrm{HIMPF}_{\mathrm{i}}=1-\frac{\mathrm{UN}_{\mathrm{S}, \mathrm{i}}+\mathrm{DN}_{\mathrm{S}, \mathrm{i}}}{2}
$$

where $\mathrm{HISPF}_{\mathrm{i}}=$ hydraulic importance of pipe $\mathrm{i}$ by multi-pipe failure; $\mathrm{UNS}_{\mathrm{i}, \mathrm{i}}=$ upstream nodal serviceability of pipe $\mathrm{i}$; DNs,i $=$ downstream nodal serviceability of pipe $\mathrm{i}$.

\subsection{Weights of Attributes}

Many studies have been conducted to examine methods for determining the weighting factors of attributes used in multi-criteria decision-making methods. These studies have shown that common usage standards do not exist among the conventional methods and that no one method stands out as better than the others. Although some studies have proposed weighting factor methods based on the type of decision-making domain, the theoretical validity of these methods has not been confirmed. Thus, it is crucial to determine appropriate weighting methods on the basis of the types and attributes of the decision-making domain and to make a reasonable decision accordingly. In this study, the five weighting methods listed in Table 1 were employed.

Table 1. Weighting methods.

\begin{tabular}{ccc}
\hline No. & References & Method \\
\hline 1 & - & Same weighting \\
2 & {$[24]$} & Eigenvector \\
3 & {$[33]$} & Churchman-Ackoff \\
4 & {$[34]$} & Rating \\
5 & {$[35,36]$} & Entropic \\
\hline
\end{tabular}

\subsubsection{Eigenvector}

The eigenvector method proposed by Saaty [24] has been used as a weighting calculation method for AHP, which is one of the main multi-criteria decision methods. Weighting factor values can be calculated using Equation (4) below. This is a widely used method, because it is easily applied and suitable for problem analysis.

$$
\mathrm{A} \varpi=\lambda_{\max } \varpi
$$

where $\mathrm{A}=$ positive pairwise comparison reciprocal matrix; $\lambda_{\max }=$ maximum eigenvalue of $\mathrm{A}$; $\varpi=$ weighting factor of the attribute. 


\subsubsection{Churchman-Ackoff Method}

The Churchman-Ackoff method [33] is based on rankings, whereby weightings are calculated via Equation (5). For example, when a problem consists of five attributes, $n$ is 5 and $\phi_{j=1}^{5} j$ is 15 . When Attributes 1 to 5 are ranked from 1st to 5 th, respectively, the weights of the attributes will be $0.33,0.27$, $0.20,0.13$ and 0.07 , in sequence.

$$
\omega_{i}=\frac{J}{\sum_{j=1}^{n} j}=\frac{2 J}{n(n+1)}
$$

where $j=$ attribute $(j=1,2, \ldots, n) ; n=$ number of attributes; $J=$ rank of the importance of the $j$-th attribute.

\subsubsection{Rating}

The rating method [34] calculates weights based on ratings received from a respondent, and calculation is performed as indicated in Equation (6). The scale of the rating can be arbitrarily established from 0 to 10 .

$$
\omega_{\mathrm{i}}=\frac{\sum_{\mathrm{k}=1}^{\mathrm{l}} \omega_{\mathrm{jk}}}{\sum_{\mathrm{j}=1}^{\mathrm{n}} \sum_{\mathrm{k}=1}^{\mathrm{l}} \omega_{\mathrm{jk}}}
$$

where $\mathrm{j}=$ attribute $(\mathrm{j}=1,2, \ldots, \mathrm{n}) ; \mathrm{n}=$ number of attributes; $\mathrm{k}=$ respondent $(\mathrm{k}=1,2, \ldots, \mathrm{l}) ; \mathrm{l}=$ number of respondents; $\omega_{j k}=\frac{r_{j k}}{\sum_{j=1}^{n} r_{j k}} ; r_{j k}=$ rating of respondent $k$.

\subsubsection{Entropic Method}

The entropic method was proposed by Hwang and Yoon [35] and Soofi [36]. It is an objective method that is used to calculate weights using only data in the decision-making domain and not using the subjective judgments of decision makers. The procedure for the entropic method starts by estimating the weight vectors from an alternative-attribute matrix. From the viewpoint of entropy, an alternative-attribute matrix contains information that can be used to estimate weights for criteria. That is, a criterion that has a large difference between alternatives is an important criterion, whereas a criterion that has a small difference between alternatives is a less important criterion. It is assumed that a decision-making domain can be represented by matrix D, shown in Equation (7) below.

$$
D=\left[\begin{array}{ccccc}
x_{11} & \cdots & x_{1 j} & \cdots & x_{1 n} \\
\vdots & \cdots & \vdots & \cdots & \vdots \\
x_{i 1} & \cdots & x_{i j} & \cdots & x_{i n} \\
\vdots & \cdots & \vdots & \cdots & \vdots \\
x_{m 1} & \cdots & x_{m j} & \cdots & x_{m n}
\end{array}\right]
$$

If $\mathrm{p}_{\mathrm{ij}}$ is a normalized result with respect to all attributes, $\mathrm{p}_{\mathrm{ij}}$ can be represented by Equation (8).

$$
p_{i j}=\frac{x_{i j}}{\sum_{i=1}^{m} x_{i j}}(i=1,2, \ldots, m ; j=1,2, \ldots, n)
$$

Assuming that the entropy of each attribute is $E_{j}$, the entropy can be calculated using Equation (9).

$$
E_{j}=-k \sum_{i=1}^{m} p_{i j} \cdot \log p_{i j}\left(k=\frac{1}{\log m}\right)
$$


To calculate the weight of an attribute, a level of diversity, $d_{j}$, is used that can be calculated using Equation (10). When these values are normalized with respect to every attribute, this represents the weight of the corresponding attribute (Equation (11)).

$$
\begin{aligned}
& d_{j}=1-E_{j} \\
& \omega_{i}=\frac{d_{j}}{\sum_{j=1}^{n} d_{j}}
\end{aligned}
$$

\subsection{Weighted Utopian Approach}

The utopian approach proposed by Xanthopulos et al. [37] can be applied whenever there are multiple attributes and offers the advantage of convenience in application. However, it suffers the drawback that calculations are performed assuming the same weights for each attribute. In general, the weights of the attributes cannot be the same during decision making. If the same weights were to be used, it would produce results and judgments that differed from those of the decision makers.

Yoo et al. [38] proposed a weighted utopian approach (WUA) that combines a weighting method for multi-criteria decision making. A schematic view of the WUA is shown in Figure 4. Assuming that there are two attributes that enter into making a decision, namely A1 and A2, a coordinate plane with two axes, can be visualized. The normalization of the attribute values of every alternative between 0 and 1 over the coordinate plane can be seen in the graph on the left-hand side of Figure 4.

Figure 4. Weighted utopian approach.

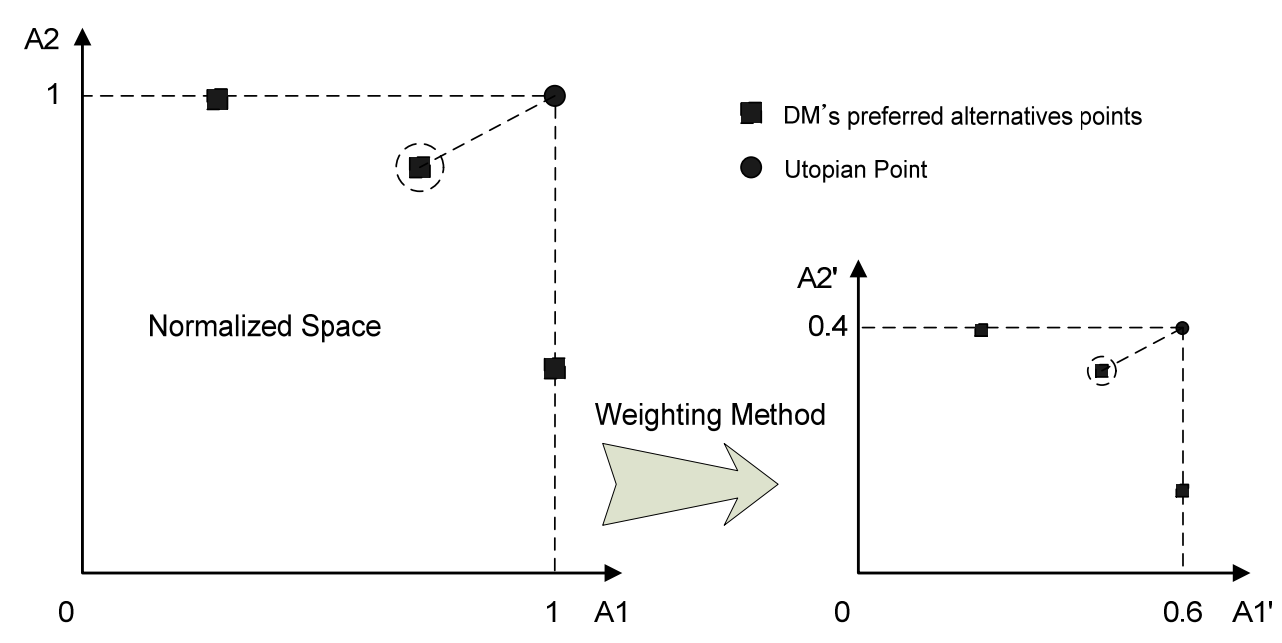

Once the weights of the attributes have been calculated using the weighting method for multi-criteria decision making, they are multiplied for each axis, so that alternative attribute and utopian point values, distributed between 0 and 1, are redistributed on a coordinate plane. For example, if the weights of A1 and A2, which were calculated using the weighting method, are 0.6 and 0.4 , respectively, the newly created utopian point on a graph changes from $(1,1)$ to $(0.6,0.4)$. Finally, using the re-distributed graph, the distance between the utopian point and the alternative is calculated. The distance measurement method used to calculate a distance employs the commonly used Euclidean distance, illustrated in Figure 5. Finally, the priority of the alternatives is determined from the values of the Euclidean distance, starting with the shortest distance. 
Figure 5. Euclidean distance.

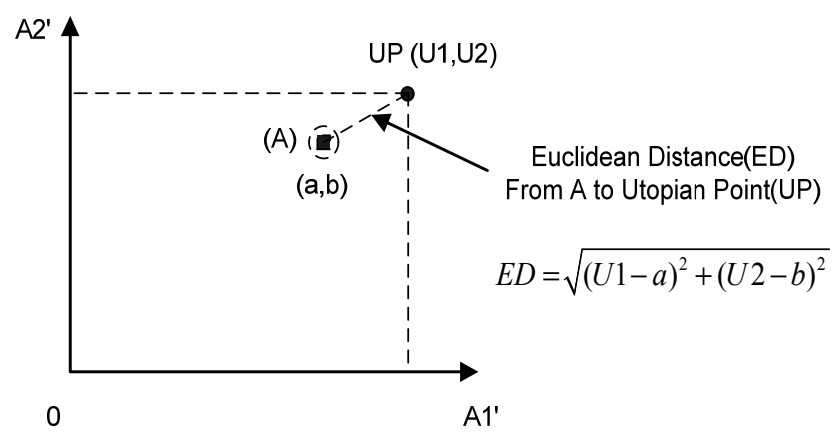

That is, the priority of each alternative is determined using a weighting method, and the final priority ranking of the alternatives is determined by sorting the average ranking values produced using the weighting method in an ascending order.

Figure 6 shows a flow chart for the model proposed in this paper for determining the rehabilitation priority order for water pipelines.

Figure 6. Flow chart for determination of rehabilitation order. WUA, weighted utopian approach.

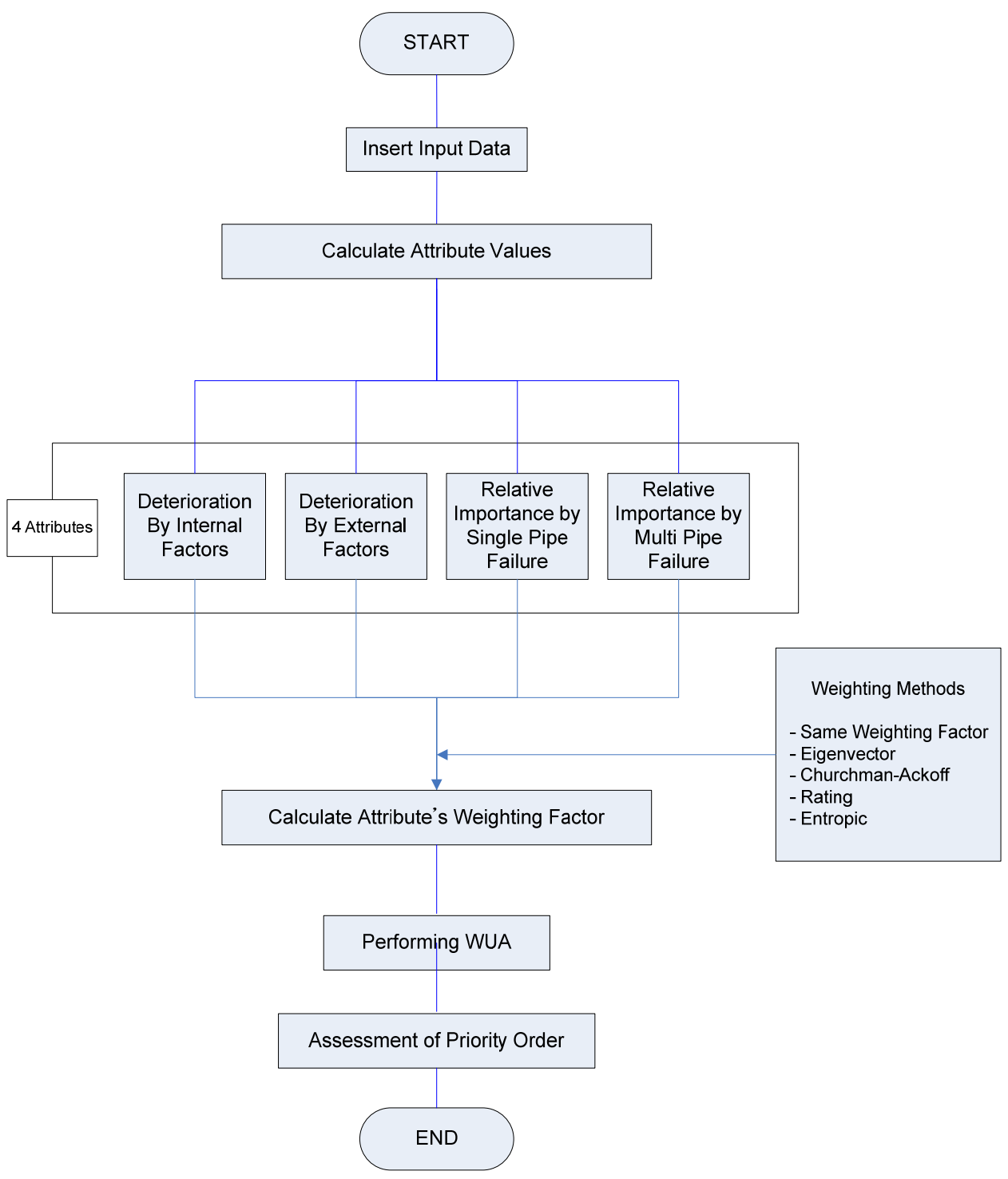




\section{Application Results}

The model proposed in this study was applied to the KA network in City J, which divides its overall water network to enable area isolation, with 10 large district meter areas and 130 small district meter areas. City $\mathrm{J}$ has established main project plans to replace and rehabilitate deteriorating water pipelines in 50 small district meter areas and to maintain the water distribution facilities. There are 350 pipelines in the KA network, which is one of the 10 large district meter areas, with a total pipeline length of $35,951 \mathrm{~km}$. The average demand per day is $16,058.4$ cubic meters per day (CMD). The number of nodes is 230 , and the number of installed valves is 160 . Figure 7 shows the locations of pipelines and nodes in the KA network. Within the network, 24 pipes have diameters greater than $300 \mathrm{~mm}$, while most of the pipes have diameters between 80 and $300 \mathrm{~mm}$.

Figure 7. KA network in City J. CMD, cubic meters per day.

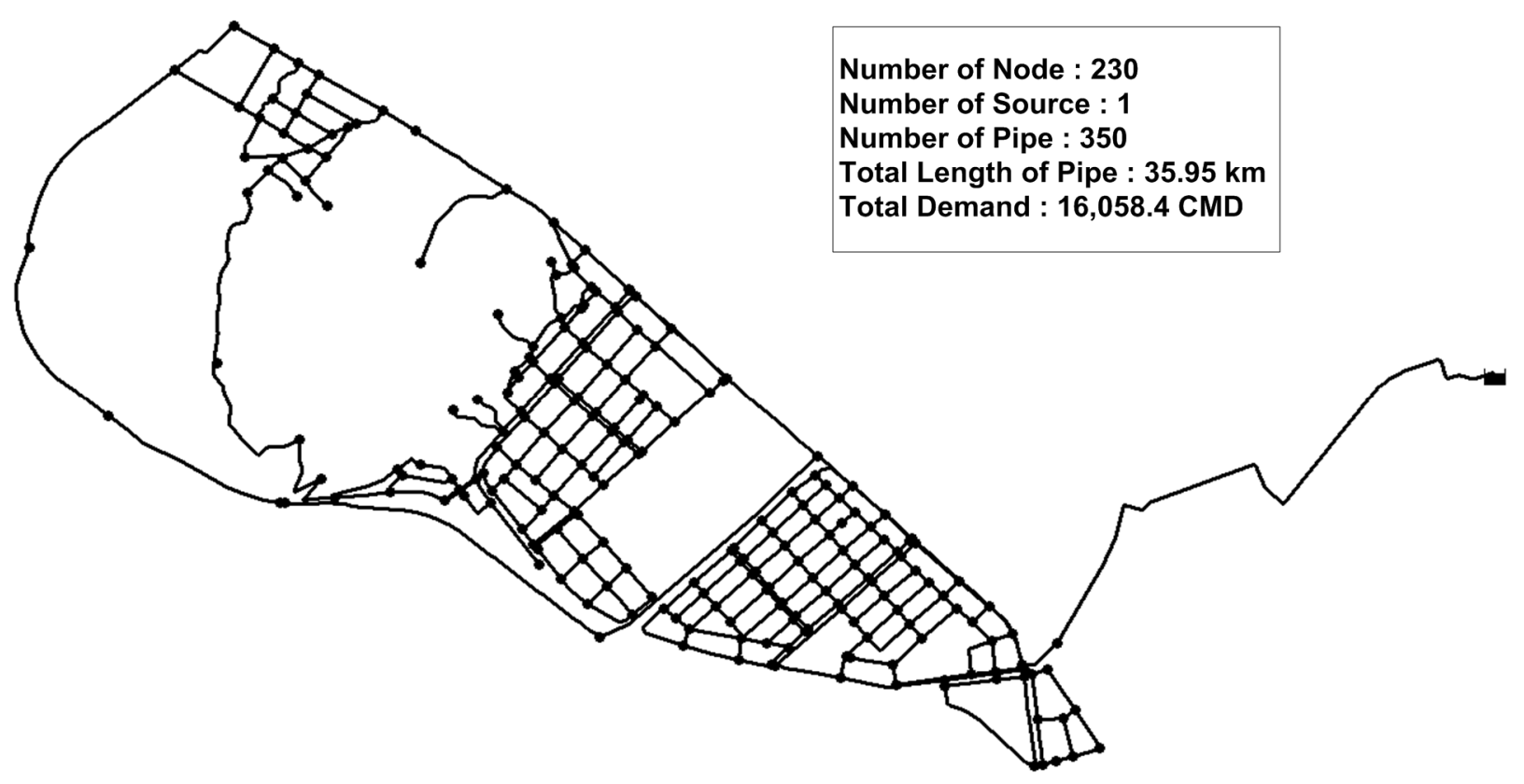

\subsection{Results: Deterioration Rate}

Input data consisting of internal factors and external factors for each pipe were acquired to calculate the deterioration rates of the water pipelines using the PNN algorithm. Scores for each factor, to be applied in the PNN algorithm, were determined according to Tables 2 and 3. In addition, the weights for each factor were obtained by applying the eigenvector method to the results of surveys of 15 experts (the results are summarized in Table 4). Of the 15 experts, five were from academia, five were from corporations and five were from research centers and government agencies. The estimates of the deterioration rates with respect to the internal factors indicated that the number of Group 1 water pipes was 250 of the 350 pipes and that the number of Group 5 water pipes was 100. The reason for such a distinctive difference can be discerned from the years of installation of the water pipes. The average number of years that had elapsed from the installation date of the Group 1 water pipes was 18.5 years, which is considerably longer than that of the Group 5 water pipes, which was four years, many of the Group 5 water pipes having recently been replaced or rehabilitated. This means that those water pipes 
for which many years had elapsed since the installation date had a greater inside corrosion rate and more frequent records of civil appeals and repairs than more recently installed water pipes. The classification of deterioration rates by installation environment/external factors placed 10 pipes in Group 2, 81 pipes in Group 3 and 259 pipes in Group 5. The main reason that most pipes were in Group 5 was that no water pipes with a significantly large exterior corrosion rate (a factor to which a large weight applied) existed. Another reason was that most of the water pipes were installed in sandy soil, which tends to inhibit deterioration. As a result, the deterioration rate associated with the installation environment/external factors was not high.

Table 2. Scores resulting from internal factors.

\begin{tabular}{|c|c|c|c|c|c|}
\hline Factor & $\begin{array}{c}\text { Detailed } \\
\text { Classification }\end{array}$ & $\begin{array}{l}\text { Scaled } \\
\text { Score }\end{array}$ & Factor & $\begin{array}{c}\text { Detailed } \\
\text { Classification }\end{array}$ & $\begin{array}{l}\text { Scaled } \\
\text { Score }\end{array}$ \\
\hline \multirow{5}{*}{ Pipe material } & $\mathrm{CI} *, \mathrm{CIP} *$ & 1.00 & \multirow{5}{*}{ Pipe diameter (mm) } & Below 80 & 1.00 \\
\hline & $\mathrm{PE}^{*}, \mathrm{PVC}^{*}$ & 0.75 & & $80-100$ & 0.75 \\
\hline & $\mathrm{SP} *$ & 0.50 & & $100-150$ & 0.50 \\
\hline & HI-3P * & 0.25 & & $150-250$ & 0.25 \\
\hline & DCIP * & 0.00 & & Above 250 & 0.00 \\
\hline \multirow{5}{*}{$\begin{array}{l}\text { Inside corrosion rate } \\
\qquad(\mathrm{mm})\end{array}$} & Below -2 & 1.00 & \multirow{5}{*}{$\begin{array}{c}\text { Installation year } \\
\text { (Installation duration, y) }\end{array}$} & Above 20 & 1.00 \\
\hline & $-2-0.5$ & 0.75 & & $15-20$ & 0.75 \\
\hline & $-0.5-0.3$ & 0.50 & & $10-15$ & 0.50 \\
\hline & $-0.3-0$ & 0.25 & & $5-10$ & 0.25 \\
\hline & Above 0 & 0.00 & & Below 5 & 0.00 \\
\hline \multirow{5}{*}{$\begin{array}{l}\text { Record of leakage or } \\
\text { valve replacement } \\
(\text { No. of cases } /(y \cdot m))\end{array}$} & Above 10 & 1.00 & \multirow{5}{*}{$\begin{array}{l}\text { Maximum pressure of } \\
\text { pipes }\left(\mathrm{kg} / \mathrm{cm}^{2}\right)\end{array}$} & Above 5 & 1.00 \\
\hline & $7-10$ & 0.75 & & $4-5$ & 0.75 \\
\hline & $3-7$ & 0.50 & & $3-4$ & 0.50 \\
\hline & $0-3$ & 0.25 & & $2-3$ & 0.25 \\
\hline & 0 & 0.00 & & Below 2 & 0.00 \\
\hline \multirow{3}{*}{ Joint type } & Welding & 1.00 & \multirow{3}{*}{$\begin{array}{l}\text { Record of a civil appeal } \\
\text { (water quality or pressure) }\end{array}$} & Yes & 1.00 \\
\hline & Rubber ring & 0.50 & & No & 000 \\
\hline & Mechanic & 0.00 & & NO & 0.00 \\
\hline
\end{tabular}

Notes: * CI/CIP: Cast Iron Pipe; PE: Poly-Ethylene Pipe; PVC: Poly-Vinyl Chloride Pipe; SP: Steel Pipe;

HI-3P: High Impact (3-Layer) Pipe; DCIP: Ductile Cast Iron Pipe.

Table 3. Scores resulting from external factors.

\begin{tabular}{|c|c|c|c|c|c|}
\hline Factor & Detailed Classification & Scaled Score & Factor & Detailed Classification & Scaled Score \\
\hline \multirow{5}{*}{$\begin{array}{c}\text { Outside } \\
\text { corrosion rate } \\
(\mathrm{mm})\end{array}$} & More than 9 & 1.00 & \multirow{5}{*}{ Road width } & Industrial road & 1.00 \\
\hline & $6-9$ & 0.75 & & 4-lane road & 0.75 \\
\hline & $4-6$ & 0.50 & & 2-land road & 0.50 \\
\hline & $2-4$ & 0.25 & & Street & 0.25 \\
\hline & Less than 2 & 0.00 & & Sidewalk and bare ground & 0.00 \\
\hline \multirow{5}{*}{$\begin{array}{l}\text { Installation } \\
\text { district }\end{array}$} & Factory & 1.00 & \multirow{5}{*}{$\begin{array}{l}\text { Refilled } \\
\text { soil type }\end{array}$} & Clay & 1.00 \\
\hline & Roadside & 0.75 & & Silt & 0.50 \\
\hline & Commercial district & 0.50 & & & \\
\hline & Apartment & 0.25 & & Sand & 0.00 \\
\hline & Residential area, farmland & 0.00 & & & \\
\hline
\end{tabular}


Table 4. Weighting values resulting from internal and external factors.

\begin{tabular}{cc}
\hline Factor & Weight \\
\hline Pipe material & 0.452 \\
Pipe diameter & 0.286 \\
Inside corrosion rate & 1.864 \\
Installation year & 1.252 \\
Joint type & 0.515 \\
Record of leakage or valve replacement & 1.848 \\
Record of a civil appeal & 1.140 \\
Maximum pressure of pipes & 0.643 \\
Outside corrosion rate & 2.015 \\
Refilled soil type & 0.680 \\
Road width & 0.610 \\
Installation district & 0.694 \\
\hline
\end{tabular}

\subsection{Results: Hydraulic Importance of Single Pipe Failure}

The number of segments, as determined by the locations of valves, calculated to estimate the importance of each water pipe in the event of a single pipe failure was found to be 50 . The average calculated importance of a water pipe when each segment failed was found to be 0.083 . This result indicates that the KA network has a low importance value in the event of a single pipe failure. This low importance value is attributable to the proper placement of the valves. However, several major segments had considerably higher levels of importance. For example, if a segment consisting of water pipes 975, 1104 and 1105 were to fail, unintended isolation would occur for as many as 174 water pipes. As a result, the importance of the corresponding pipes was calculated to be 0.6340 , which is extremely high. As such, a high relative importance, such as that calculated for the above example, was generated in a total of four cases, except for those water pipes for which the water is received directly from the water source. These four segments are described in Table 5 and Figure 8. Water pipes that belong to such segments can present a major risk when breakage or emergency situations occur. Accordingly, they must always be carefully maintained and monitored. However, the importance of the other segments, which had a small number of water pipes and which did not give rise to unintended isolation (UI), was low.

Table 5. Value of importance of segment in the event of single pipe failure. UI, unintended isolation.

\begin{tabular}{cccc}
\hline Segment & Pipe ID & No. of Pipes by UI & Importance \\
\hline 1 & $975,1104,1105$ & 174 & 0.6340 \\
2 & 976 & 174 & 0.5868 \\
3 & 1005,1118 & 98 & 0.4582 \\
4 & 1059 & 184 & 0.4156 \\
\hline
\end{tabular}


Figure 8. Importance of segments by single pipe failure.

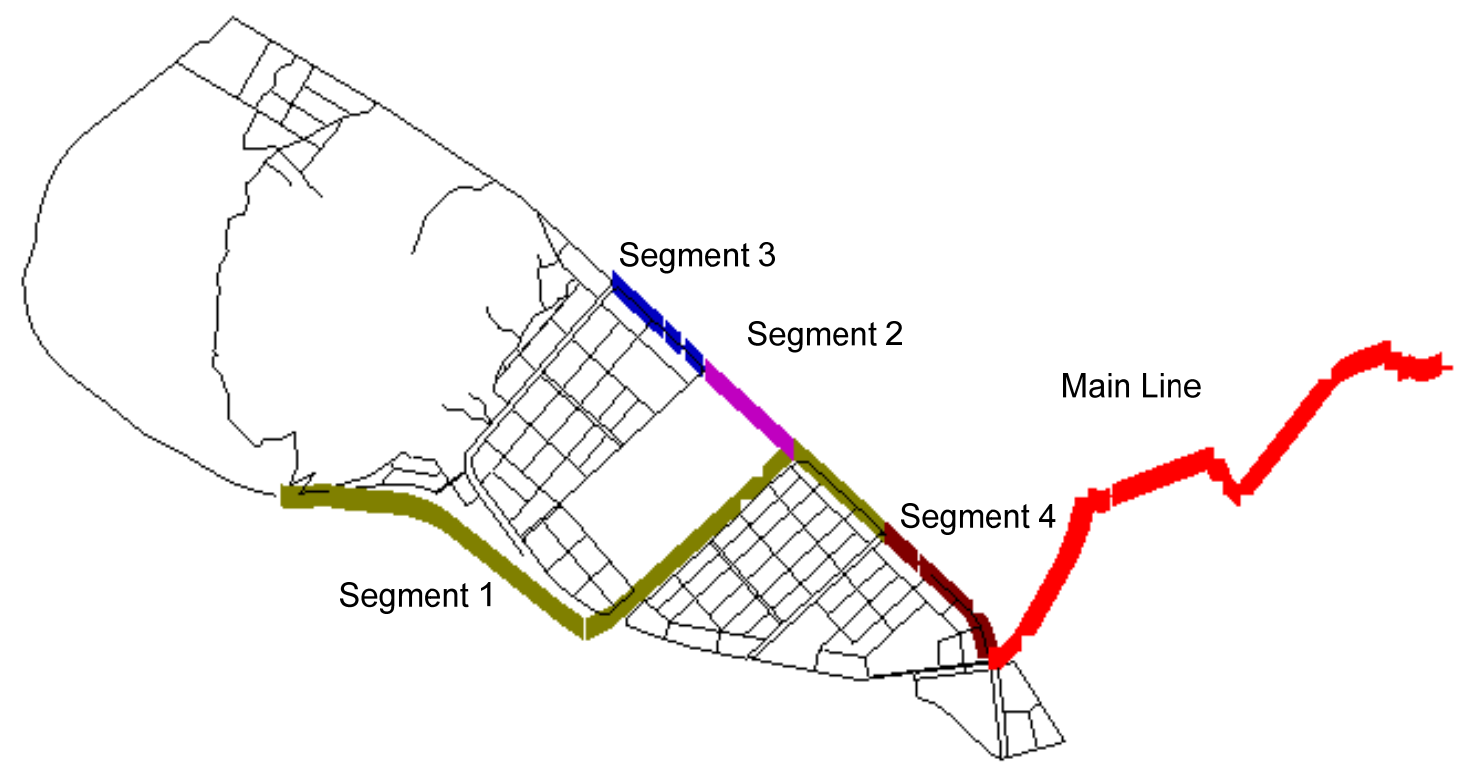

\subsection{Results: Hydraulic Importance of Multiple Pipe Failures}

The REVAS.NET model was used in this study to calculate the importance of water pipes in the event of multiple pipe failures. As shown in Table 6, a previous earthquake of magnitude M7 that had occurred in Province J, which includes the KA network, was considered. The execution number for the Monte Carlo simulation was set to 10,000 , while the minimum pressure in the KA network was considered to be 15 m (KWWA [39]).

Table 6. Reliability evaluation scenario and results for the KA network.

\begin{tabular}{|c|c|c|}
\hline \multicolumn{2}{|c|}{ Seismic Hazard } & \multirow{2}{*}{$\begin{array}{l}\text { Nodal Serviceability } \\
\text { (Average Value) }\left(\mathbf{N}_{\mathrm{S}}\right)\end{array}$} \\
\hline $\begin{array}{l}\text { Historical Location Data } \\
\text { (Number of Data Points) }\end{array}$ & Magnitude & \\
\hline J Province (29) & Specific Magnitude $(\mathrm{M}=7)$ & 0.662 \\
\hline
\end{tabular}

The results obtained with REVAS.NET indicate that the average system serviceability $\left(\mathrm{S}_{\mathrm{S}}\right)$ and nodal serviceability (Ns) were 0.533 and 0.662 , respectively. Figure 9 depicts the spatial distribution of the nodal serviceability and shows that the reliability was relatively low at the nodes of the terminal area, which are far from the water source and which are branched into a single path. One of the key features of this figure is that the reliability of the system appears to be almost as high as in the case of completely looped segments. This means that looped segments can secure various paths by which water is supplied, so that rapid service degradation, even in the event of the breakage of some pipes, can be prevented.

To confirm the importance of the water pipes more accurately, 20 major water pipelines were marked as shown in Figure 10. The figure shows that the serviceability of the water pipes in the terminal area, which ultimately branches into a single path, was very low. Therefore, these areas require rehabilitation work to improve the durability or diversification of the water supply paths. 
Figure 9. Nodal serviceability of the KA network.

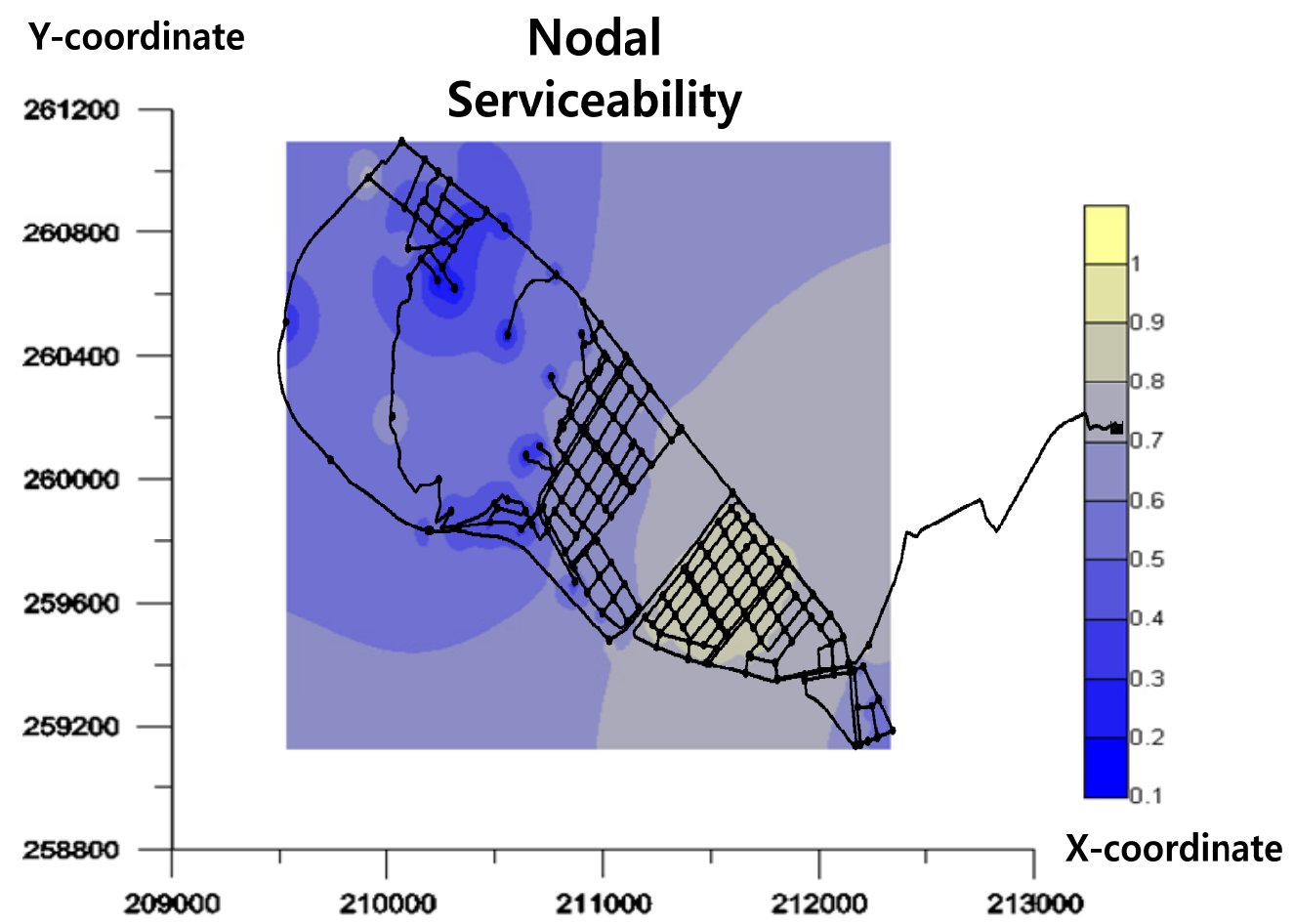

Figure 10. Importance of pipes by multi-pipe failure.

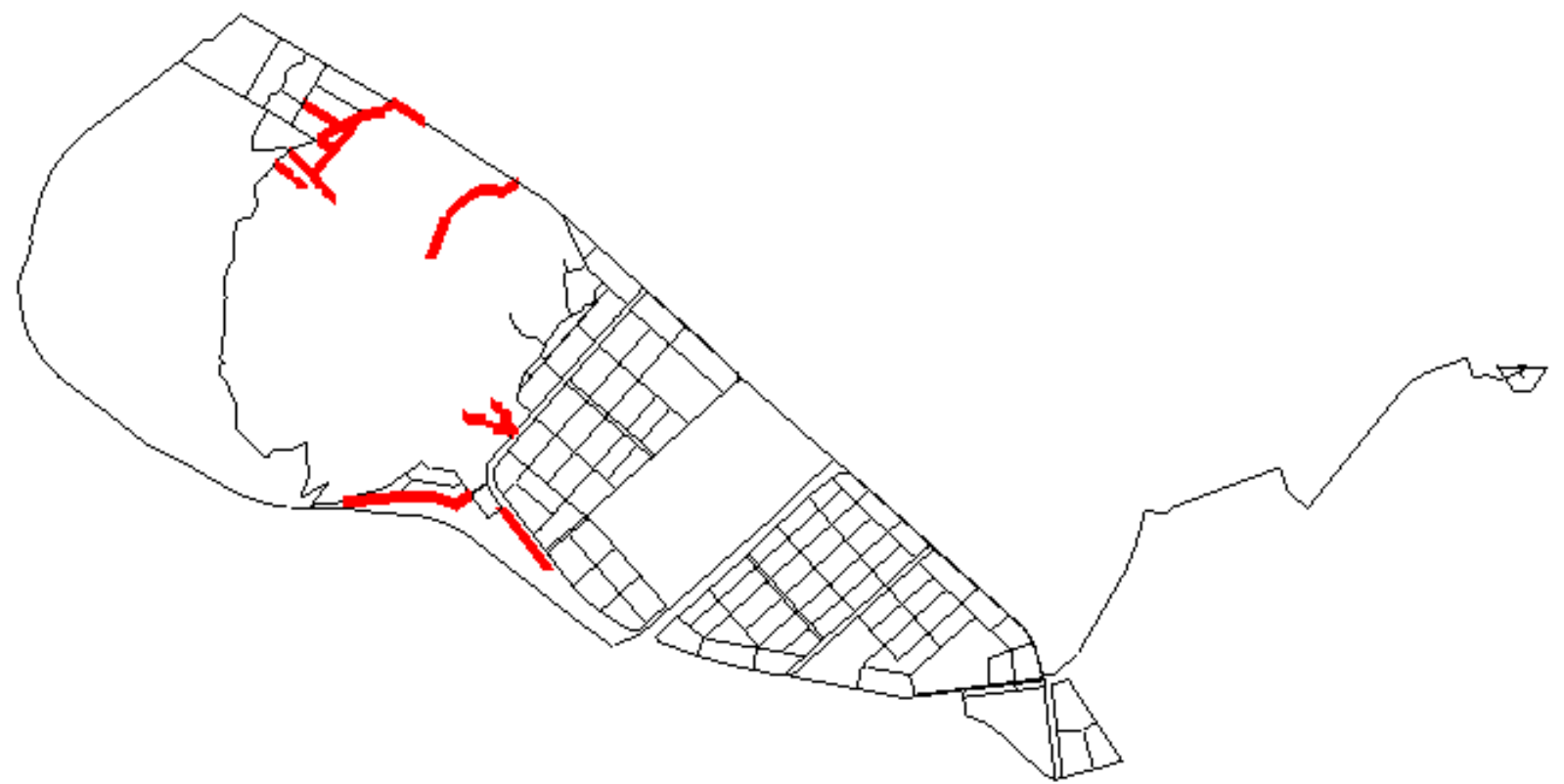

\subsection{Results for Final Rehabilitation Priority Order}

Table 7 summarizes the statistical values of four attributes. Based on the deterioration rate, the relative importance, the weighted utopian approach was used to calculate the rehabilitation priority order of individual water pipes. 
Table 7. Statistical value of attributes of deterioration and importance.

\begin{tabular}{cccccc}
\hline \multirow{2}{*}{$\begin{array}{c}\text { Statistical } \\
\text { Indicator }\end{array}$} & Internal Factor & \begin{tabular}{c} 
Deterioration Rate \\
\cline { 2 - 3 }
\end{tabular} & $\begin{array}{c}\text { Installation } \\
\text { Environments/External Factor }\end{array}$ & Single Pipe Failure & Multiple Pipe Failure \\
\hline Average & 0.7036 & 0.1470 & 0.0556 & 0.0832 & 0.3179 \\
Variance & 0.1963 & 0.7111 & 0.0090 & 0.0232 \\
Max value & 1.0000 & 0.0039 & 0.6340 & 0.8126 \\
Min value & 0.0039 & 0.0001 & 0.0744 \\
\hline
\end{tabular}

Five weighting methods were used to apply the weighted utopian approach. The weighting factors of the attributes used in four of the methods (excluding the entropic method) were based on the results of the survey of 15 experts in the field of water distribution systems (the results are listed in Table 8). As with the survey concerning the weighting factors for the deterioration rate, the 15 experts consisted of five from academia, five from corporations and five from research centers and government agencies.

Table 8. Weighting factors of attributes depending on weighting methods.

\begin{tabular}{ccccc}
\hline \multirow{2}{*}{ Weighting Method } & \multicolumn{3}{c}{ Weighting Factor } \\
\cline { 2 - 5 } & $\begin{array}{c}\text { Deterioration by } \\
\text { Internal Factors }\end{array}$ & $\begin{array}{c}\text { Deterioration by } \\
\text { External Factors }\end{array}$ & $\begin{array}{c}\text { Relative Importance } \\
\text { by Single Pipe Failure }\end{array}$ & $\begin{array}{c}\text { Relative Importance by } \\
\text { Multi Pipe Failure }\end{array}$ \\
\hline Same Weighting & 0.250 & 0.250 & 0.250 & 0.250 \\
Eigenvector & 0.344 & 0.097 & 0.349 & 0.210 \\
Churchman-Ackoff & 0.400 & 0.200 & 0.300 & 0.100 \\
Rating & 0.351 & 0.220 & 0.268 & 0.162 \\
Entropic & 0.155 & 0.549 & 0.246 & 0.050 \\
\hline
\end{tabular}

Table 9 lists the weighting methods used and the resulting priority orders obtained for the rehabilitation of the top 20 water pipes, after applying the WUA. The results obtained using the five weighting methods indicate that the eigenvector, Churchman-Ackoff and rating methods produced similar results, whereas the same weighting and entropic methods produced results that were somewhat different from those obtained with the other three methods. Accordingly, the redundancy of the top 20 water pipes was investigated, and the results confirmed that a total of five water pipes were identified as priorities by all five methods and that a total of 14 water pipes overlapped in more than three of the methods. As described above, the rehabilitation priorities changed slightly as the weights were adjusted. These results indicate that although the superiority of any one of the weighting methods (whereby each of their axiomatic systems has been verified both logically and independently) cannot be determined, the sensitivity to any change in the weighting factors should be taken into account when a decision or rehabilitation prioritization is made. Hence, the proposed model offers not only the advantage of being representative, but also generality among multi-criteria decision-making methods, as it considers several methods of determining weighting factors with diverse characteristics. The proposed method can also provide final total results, as well as the results for each weighting method for consideration by final decision makers, thereby providing a wide range of alternatives depending on the context. That is, if there are attributes that must be considered depending on the decision-making environment and the characteristics of the issues, a specific weighting 
method can also be used to produce a priority ranking other than the priority ranking produced by the model developed in this study.

In this study, the final rehabilitation priority order was determined based on the average ranking for each water pipe, selected using the five weighting methods. The final results for the top 20 water pipes are shown in Figure 11 and Table 10. Although the results do not exhibit a clear trend, the rehabilitation priority order of the water pipes that are directly connected to the water source or that connect networks tended to receive high priority rankings. Water pipes other than those described above also generally ranked highly in terms of rehabilitation priority because of the effect of the deterioration rate determined from internal factors, for which the weighting values were set high as a result of the survey results. The deterioration rate values resulting from the internal and external factors showed that most of the values for the top 20 water pipes were high and that their variation was not considerable. However, the importance of single and multiple failures showed that the variation in the deterioration rates for the top 20 water pipes was relatively large. This result reflects the characteristics of the distribution of low factor values in most cases, except for some segments, in the case of a single failure. However, in the case of multiple failures, because the weighting values used to calculate the final rehabilitation priority order were not sufficiently large, the effect on the final rehabilitation priority order was minimal, even if the importance value resulting from multiple failures is large, which is why the variation for the top 20 values was large and unevenly distributed.

Table 9. Priority order for rehabilitation according to weighting methods.

\begin{tabular}{cccccc}
\hline $\begin{array}{c}\text { Rehabilitation } \\
\text { Priority Order }\end{array}$ & Same Weighting & Eigenvector & Churchman-Ackoff & Rating & Entropic \\
\hline 1 & 1105 & 1105 & 1105 & 1105 & 1088 \\
2 & 1197 & 975 & 977 & 977 & 1073 \\
3 & 1236 & 1104 & 1104 & 1197 & 1236 \\
4 & 1220 & 976 & 975 & 1220 & 1105 \\
5 & 1018 & 1118 & 976 & 1104 & 1040 \\
6 & 1153 & 1005 & 1118 & 1018 & 977 \\
7 & 909 & 977 & 1005 & 975 & 986 \\
8 & 977 & 1197 & 1197 & 1236 & 1153 \\
9 & 1121 & 1220 & 1220 & 976 & 909 \\
10 & 1241 & 1009 & 1018 & 1088 & 1132 \\
11 & 1213 & 1013 & 1088 & 1073 & 1128 \\
12 & 1001 & 1015 & 1073 & 1153 & 1181 \\
13 & 1132 & 1014 & 1206 & 1118 & 1197 \\
14 & 999 & 1018 & 937 & 1206 & 1206 \\
15 & 1000 & 1011 & 959 & 909 & 937 \\
16 & 1002 & 1017 & 950 & 959 & 959 \\
17 & 1226 & 1019 & 931 & 937 & 950 \\
18 & 997 & 1236 & 930 & 1005 & 931 \\
19 & 995 & 1206 & 1097 & 950 & 930 \\
20 & 1199 & 959 & 912 & 930 & 1097 \\
\hline
\end{tabular}


Figure 11. Top 20 pipes to be rehabilitated.

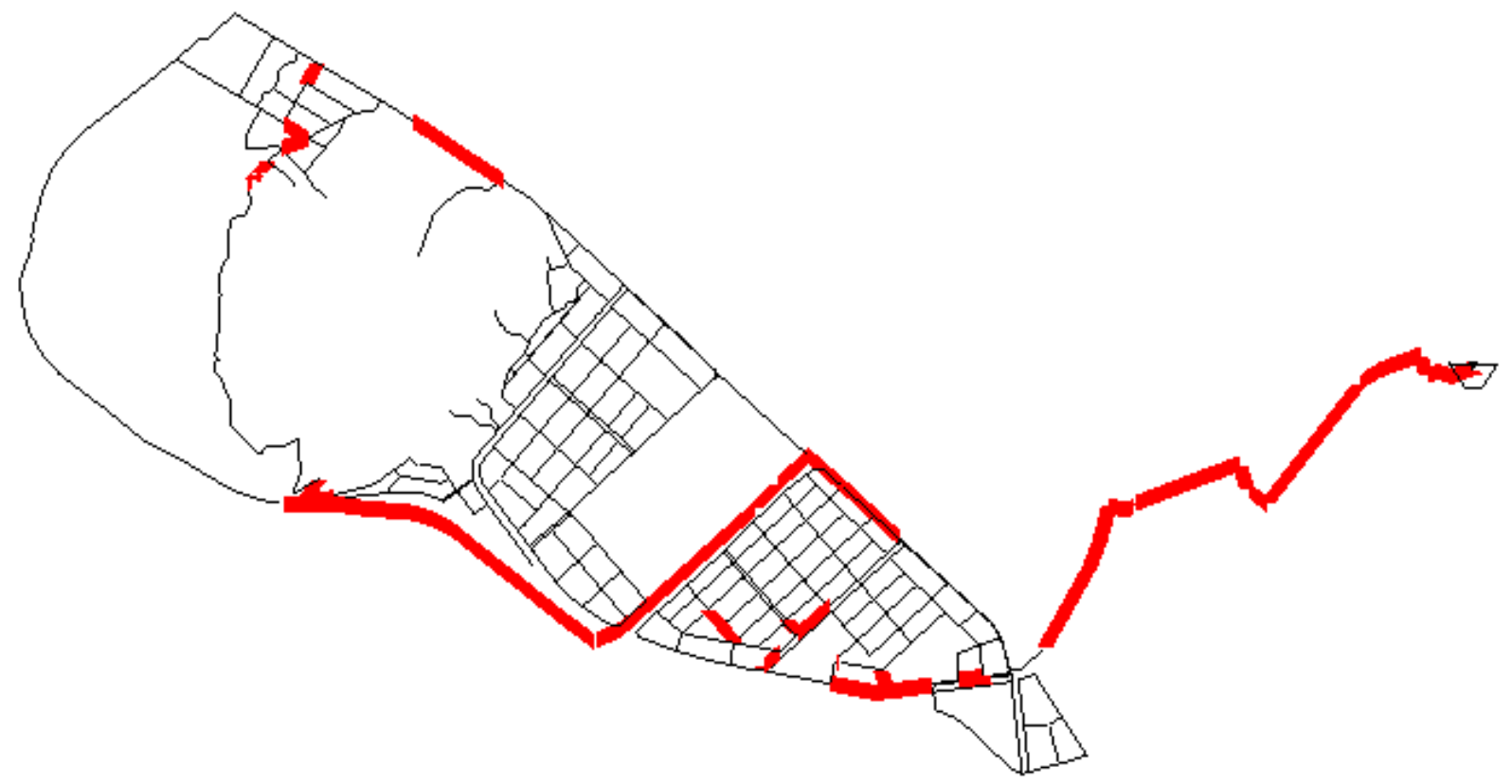

Table 10. Values of four attributes according to rehabilitation order.

\begin{tabular}{ccccc}
\hline $\begin{array}{c}\text { Rehabilitation } \\
\text { Priority Order }\end{array}$ & $\begin{array}{c}\text { Deterioration by } \\
\text { Internal Factors }\end{array}$ & $\begin{array}{c}\text { Deterioration by } \\
\text { External Factors }\end{array}$ & $\begin{array}{c}\text { Relative Importance } \\
\text { by Single Pipe Failure }\end{array}$ & $\begin{array}{c}\text { Relative Importance } \\
\text { by Multi Pipe Failure }\end{array}$ \\
\hline 1105 & 0.9997 & 0.5187 & 0.6340 & 0.2524 \\
977 & 0.9905 & 0.5158 & 0.5538 & 0.0744 \\
1197 & 0.9997 & 0.5332 & 0.1572 & 0.6167 \\
1220 & 0.9975 & 0.5158 & 0.1572 & 0.5729 \\
1236 & 0.9975 & 0.7111 & 0.0624 & 0.6172 \\
1018 & 0.9995 & 0.5158 & 0.1572 & 0.4845 \\
1088 & 0.9978 & 0.7111 & 0.1292 & 0.1686 \\
1073 & 0.9978 & 0.7111 & 0.1292 & 0.1668 \\
1206 & 0.9642 & 0.5332 & 0.1292 & 0.2620 \\
959 & 0.9642 & 0.5332 & 0.1292 & 0.2476 \\
937 & 0.9997 & 0.5332 & 0.1292 & 0.2426 \\
950 & 0.9940 & 0.5332 & 0.1292 & 0.2122 \\
930 & 0.9642 & 0.5332 & 0.1292 & 0.1995 \\
931 & 0.9905 & 0.5332 & 0.1292 & 0.1960 \\
1153 & 0.9996 & 0.7111 & 0.0039 & 0.6181 \\
909 & 0.9998 & 0.7111 & 0.0030 & 0.5858 \\
1104 & 0.9990 & 0.0569 & 0.6340 & 0.2232 \\
975 & 0.9998 & 0.0069 & 0.6340 & 0.2908 \\
1097 & 0.9940 & 0.5332 & 0.1292 & 0.1676 \\
912 & 0.9940 & 0.5332 & 0.1292 & 0.1670 \\
\hline
\end{tabular}

\section{Conclusions}

To determine the rehabilitation priority order for pipes in a water distribution system, we developed a new method to address the limitations of existing methods that use only the pipeline deterioration rate. We 
aimed to determine the priority of pipes for rehabilitation consider normal and abnormal conditions using multi-criteria decision making methods (using compromise of some weighting methods). In this study, we also added single and multiple pipe failures simulation in addition to the deterioration of pipes. These are key points of this manuscript. The proposed method considers the hydraulic importance in addition to the deterioration rate in determining the rehabilitation priority order with higher reliability. The results of this study are significant in that they show how a rehabilitation priority order model can be combined with the concept of the hydraulic importance of water pipes in applying existing deterioration rate calculation methods to determine the rehabilitation priority order. The proposed method was applied to the KA water distribution network of City $J$ to determine the rehabilitation priority order for the pipes in the KA network. The results confirm that the proposed method provides a more realistic determination of the rehabilitation priority order that considers not only the deterioration rate, but also the relative hydraulic importance of each pipe. This model is able to determine the rehabilitation priority order for pipes in a water distribution network and can be applied more easily than existing rehabilitation priority order models that require large amounts of data and involve complex failure probabilities and mathematical models.

Because large-scale infrastructure networks, such as water distribution systems, require constant maintenance and rehabilitation, the design and reinforcement of water distribution networks to guard against multiple failures in the event of events, such as earthquakes, place huge financial and physical burdens on the water supplier. Korea has never experienced large-scale earthquakes, and most Koreans believe that their country has little to fear in this respect. However, although the probability of a disaster, such as an earthquake in Korea, is low, such an event would cause significant damage if it were to occur. Thus, Korea needs to be prepared for such disasters. Given these circumstances, a method that can determine the level of reliability of a water distribution system in the face of a disaster capable of causing immense damage is necessary within the current framework of maintenance and rehabilitation. The proposed model is also advantageous from this perspective.

The results of this study suggest that further research on this subject is warranted. The proposed method should be compared with other recent methodologies, such as CARE-W, CASSES and AWARE-P. Therefore, a detailed comparative study can be one of the further studies in the near future. The possible malfunction of valves was not considered in calculating the relative importance of structural failures. Because the area in which damage may occur varies depending on the ability to operate the relevant valve, the effect of valve malfunctioning should be studied. In this study, given that water distribution systems are essential social infrastructure networks that directly affect public welfare, an economic feasibility analysis for cost optimization purposes was not performed. Therefore, further studies on rehabilitation prioritization with consideration of economic constraints should be undertaken.

\section{Acknowledgments}

This work was supported by a grant from the National Research Foundation (NRF) of Korea, funded by the Korean government (Ministry of Science, ICT and Future Planning, MSIP) (No. 2013R1A2A1A01013886). 


\section{Author Contributions}

Do Guen Yoo and Doosun Kang carried out the survey of previous studies, analysis of proposed method, participated in the sequence alignment and drafted the manuscript; Joong Hoon Kim and Hwandon Jun conceived the original idea of the study, and helped to write the final manuscript.

\section{Conflicts of Interest}

The authors declare no conflict of interest.

\section{References}

1. American Water Works Association Research Foundation (AWWARF). Guidance Manual Water Mains Evaluation for Rehabilitation/Replacement; AWWARF: Denver, CO, USA, 1986.

2. Water Research Centre (WRC). Planning the Rehabilitation of Water Distribution Systems; WRC: Marlow, UK, 1989.

3. K-Water. Development of Decision-Making System for Pipe Rehabilitation; K-Water: Daejeon, Korea, 1995.

4. Kim, E.S.; Baek, C.W.; Kim, J.H. Estimate of Pipe Deterioration and Optimal Scheduling of Rehabilitation. Water Sci. Technol. Water Supply 2005, 5, 39-46.

5. Shamir, U.; Howard, C.D. An Analytic Approach to Scheduling Pipe Replacement. J. Am. Water Works Assoc. 1979, 71, 248-258.

6. Marks, D.H.; Clark, M.R. A New Methodology for Modeling Break Failure Patterns in Deteriorating Water Distribution Systems: Theory. Adv. Water Resour. 1987, 10, 2-10.

7. Marks, D.H.; Clark, M.R. A New Methodology for Modelling Break Failure Patterns in Deteriorating Water Distribution Systems: Applications. Adv. Water Resour. 1987, 10, 11-20.

8. Agbenowosi, N.K. A Mechanistic Analysis Based Decision Support System for Scheduling Optimal Pipeline Replacement. Ph.D. Thesis, Virginia Polytechnic Institute and State University, Blacksburg, VA, USA, September 2000.

9. Park, S.; Loganathan, G.V. Methodology for Economically Optimal Replacement of Pipes in Water Distribution Systems: 1. Theory. KSCE J. Civil Eng. 2002, 6, 539-543.

10. Park, S.; Loganathan, G.V. Methodology for Economically Optimal Replacement of Pipes in Water Distribution Systems: 2. Application. KSCE J. Civil Eng. 2002, 6, 545-550.

11. Deb, A.K.; Hasit, Y.J.; Grablutz, F.M.; Herz, R.K. Quantifying Future Rehabilitation and Replacement Needs of Water Mains; Report to the American Water Works Association Research Foundation; Roy F. Weston, Inc.: West Chester, PA, USA, 1997.

12. Walski, T.M. Economic Analysis of Rehabilitation of Water Mains. J. Water Resour. Plan. Manag. 1982, 108, 296-304.

13. Luong, H.T.; Fujiwara, O. Fund Allocation Model for Pipe Repair Maintenance in Water Distribution Networks. Eur. J. Oper. Res. 2002, 136, 403-421.

14. Alvisi, S.; Franchini, M. Near Optimal Rehabilitation Scheduling of Water Distribution Systems based on Multi-objective Genetic Algorithms. Civil Eng. Environ. Syst. 2006, 23, 143-160. 
15. Saegrov, S. Computer Aided Rehabilitation of Water Networks; IWA Publishing: London, UK, 2005; ISBN 1843390914.

16. National Civil Engineering Laboratory. CARE-W WP1 D1 Construction of Control Panel for Performance Indicators for Rehabilitation; EVK1-CT-2000-00053, No. 1.1; Research and Technological Development Project of European Community, European Commission: Brussels, Belgium, 2001.

17. National Civil Engineering Laboratory. CARE-W WP1 D2 Description of Technical Tools for Failure Forecasting and Network Reliability; EVK1-CT-2000-00053, No. 1.2; Research and Technological Development Project of European Community, European Commission: Brussels, Belgium, 2002.

18. Cemagref Bordeaux. CARE-W WP2 D3 Description and Validation of Technical Tools: Models Description; EVK1-CT-2000-00053, No. 2.1; Research and Technological Development Project of European Community, European Commission: Brussels, Belgium, 2002.

19. INSA Lyon-URGC. CARE-W WP3 D6 Decision Support for Annual Rehabilitation Programs: Criteria for the Prioritization of Rehabilitation Projects; EVK1-CT-2000-00053, No. 3.1; Research and Technological Development Project of European Community, European Commission: Brussels, Belgium, 2002.

20. INSA Lyon-URGC. CARE-W WP3 D6 Decision Support for Annual Rehabilitation Programs: Survey of Multi-Criteria Techniques and Selection of Relevant Procedures; EVK1-CT-2000-00053, No. 3.2; Research and Technological Development Project of European Community, European Commission: Brussels, Belgium, 2002.

21. Technique University Dresden. CARE-W WP4 D9 Development of the "Rehab Strategy Manager" Software; EVK1-CT-2000-00053, No. 4.2; Research and Technological Development Project of European Community, European Commission: Brussels, Belgium, 2002.

22. Cemagref (2008) CASSES, User Manual. Available online: http://casses.irstea.fr/wp-content/ uploads/2013/02/CassesManual_2.0.0_b.pdf (accessed on 1 November 2014).

23. AWARE-P (2012). The AWARE-P project-Infrastructure asset management of urban water services. Impact report for application to the 2012 Muelheim Water Award. Available online: http://www.aware-p.org/np4/?newsId=13\&fileName=MWA_AWARE_P_Application_compressed. pdf (accessed on 1 November 2014).

24. Saaty, T.L. The Analytic Hierarchy Process; McGraw-Hill: New York, NY, USA, 1980.

25. Specht, D.F. Probabilistic Neural Network. Neural Netw. 1990, 3, 109-118.

26. Jun, H.; Loganathan, G.V.; Kim, J.H.; Park, S. Identifying Pipes and Valves of High Importance for Efficient Operation and Maintenance of Water Distribution Systems. Water Resour. Manag. 2008, 22, 719-736.

27. Walski, T.M. Water Distribution Valve Topology for Reliability Analysis. Reliab. Eng. Syst. Saf. 1993, 42, 21-27.

28. Yoo, D.G.; Kang, D.; Kim, J.H. Seismic Reliability Assessment Model of Water Supply Networks. In Proceedings of the World Environmental and Water Resources Congress, Cincinnati, OH, USA, 19-23 May 2013; pp. 955-966. 
29. Yoo, D.G.; Kang, D.; Kim, J.H. Applications of Seismic Reliability Assessment Model for Water Distribution Networks. In Proceedings of the World Environmental and Water Resources Congress, Portland, OR, USA, 1-5 June 2014.

30. Cullinane, M.J.; Lansey, K.E.; Mays, L.W. Optimization-Availability-Based Design of Water-Distribution Networks. J. Hydraul. Eng. 1992, 118, 420-441.

31. Tabucchi, T.; Davidson, R.; Brink, S. Simulation of Post-Earthquake Water Supply System Restoration. Civil Eng. Environ. Syst. 2010, 27, 263-279.

32. Lansey, K.E. Sustainable, Robust, Resilient, Water Distribution Systems. In Proceedings of the 14th Water Distribution Systems Analysis Symposium, Engineers Australia, Adelaide, Australia, 24-27 September 2012.

33. Knoll, A.L.; Engelberg, A. Weighting Multiple Objectives-The Churchman-Ackoff Techniques Revisited. Comput. Oper. Res. 1978, 5, 165-177.

34. Eckenrode, R.T. Weighting Multiple Criteria. Manag. Sci. 1965, 12, 180-192.

35. Hwang, C.L.; Yoon, K. Multiple Attribute Decision Making Methods and Applications: A State-of-The-Art Survey; Springer-Verlag: New York, NY, USA, 1981.

36. Soofi, E.S. Generalized Entropy-Based Weight for Multi-Attribute Models. Oper. Res. 1990, 32, 362-363.

37. Xanthopulos, Z.; Melachrinoudis, E.; Solomon, M.M. Interactive Multiobjective Group Decision Making with Interval Parameters. Manag. Sci. 2000, 46, 1721-1732.

38. Yoo, D.G.; Kim, J.H.; Jun, H. Determination of Rehabilitation Priority Order of Subareas in Water Distribution Systems Considering the Relative Importance of Pipes; Water Distribution Systems Analysis 2010; Americal Society of Civil Engineers: Reston, VA, USA 2010; pp. 1045-1052.

39. Korea Water and Wastewater works Association (KWWA). Water Supply Facility Standard; Ministry of Environment: Seoul, Korea, 2010.

(C) 2014 by the authors; licensee MDPI, Basel, Switzerland. This article is an open access article distributed under the terms and conditions of the Creative Commons Attribution license (http://creativecommons.org/licenses/by/4.0/). 